\title{
Forest canopy interactions with nucleation mode particles
}

\author{
S. C. Pryor ${ }^{1}$, K. E. Hornsby ${ }^{2}$, and K. A. Novick ${ }^{3}$ \\ ${ }^{1}$ Department of Earth and Atmospheric Sciences, Cornell University, Ithaca, NY 14853, USA \\ ${ }^{2}$ Atmospheric Science Program, Department of Geological Sciences, Indiana University, Bloomington, IN 47405, USA \\ ${ }^{3}$ School of Public and Environment Affairs, Indiana University, Bloomington, IN 47405, USA
}

Correspondence to: S. C. Pryor (sp2279@cornell.edu)

Received: 15 May 2014 - Published in Atmos. Chem. Phys. Discuss.: 4 July 2014

Revised: 29 September 2014 - Accepted: 6 October 2014 - Published: 14 November 2014

\begin{abstract}
Ultrafine particle size distributions through a deciduous forest canopy indicate that nucleation mode particle concentrations decline with depth into the canopy, such that number concentrations at the bottom of the canopy are an average of $16 \%$ lower than those at the top. However, growth rates of nucleation mode particles (diameters 6-30 nm) are invariant with height within the canopy, which implies that the semi-volatile gases contributing to their growth are comparatively well-mixed through the canopy. Growth rates of nucleation mode particles during a meteorological drought year (2012) were substantially lower than during a meteorologically normal year with high soil water potential (2013). This may reflect suppression of actual biogenic volatile organic compound (BVOC) emissions by drought and thus a reduction in the production of condensable products during the drought-affected vegetation season. This hypothesis is supported by evidence that growth rates during the normal year exhibit a positive correlation with emissions of BVOC modeled on observed forest composition, leaf area index, temperature and photosynthetically active radiation (PAR), but particle growth rates during the drought-affected vegetation season are not correlated with modeled BVOC emissions. These data thus provide indirect evidence that drought stress in forests may reduce BVOC emissions and limit growth of nucleation mode particles to climate-relevant sizes.
\end{abstract}

\section{Introduction and objectives}

Deciduous forest canopies are both a source of compounds that may facilitate growth of nucleation mode particles to climate-relevant sizes (e.g., oxidation products of biogenic volatile organic compounds, BVOCs), and also a strong sink for nucleation mode particles due to the large surface area, high foliar uptake efficiencies and generally high turbulence intensity. However, the role that forests play in ultrafine particle budgets and thus in direct and indirect climate forcing remains uncertain. Two years of particle size distribution (PSD) measurements at three heights within and above a deciduous forest canopy are analyzed herein to quantify both the canopy uptake of ultrafine particles and the role of the canopy in particle growth, with a specific focus on differences in a drought-affected and non-drought year.

The chemical speciation and quantity of BVOC emissions vary greatly across ecosystems. But BVOC emissions are estimated to release $\sim 1-2 \%$ of photosynthetically fixed carbon $(\mathrm{C})$ back to the atmosphere over temperate deciduous forests (Kesselmeier et al., 2002). Emissions of monoterpenes and sesquiterpenes exhibit an exponential dependence on air temperature $(T)$, scale with leaf area index (LAI) and vary with plant functional type (Guenther et al., 1993). Isoprene emissions exhibit an additional dependence on photosynthetically active radiation (PAR) (Guenther et al., 2006). BVOC emissions also depend on leaf age. For example, isoprene emissions are delayed relative to the onset of photosynthesis and older leaves lose their ability to photosynthesize and produce isoprene (Guenther et al., 1991). Finally, there is evidence that BVOC emissions are also controlled by the presence and severity of physiologic stressors, and that prolonged drought may suppress BVOC emissions (Niinemets, 2010).

Previous research over temperate forests has reported the mass of organic compounds in sub-micron particles increases with $T$ (Leaitch et al., 2011). Further, there is evidence that oxidation products of BVOC are responsible for a non- 
negligible fraction of the growth of nucleation mode particles to climate-relevant sizes (Kulmala et al., 2004). This has led to the development of a theorem of an organic aerosol negative climate feedback mechanism that may offset some fraction of the greenhouse gas induced warming at the regional scale. It is important to acknowledge that production of semi-volatile condensable products from BVOC oxidation varies with the specific terpene emitted and oxidant concentrations (Barthelmie and Pryor, 1999; Iinuma et al., 2013; Hallquist et al., 2009) and thus the importance of BVOC to nano-particle growth varies greatly with different chemical climates and forest biomes. Nevertheless, in brief, the postulated feedback is as follows: as atmospheric temperatures increase due to enhanced atmospheric concentrations of carbon dioxide $\left(\mathrm{CO}_{2}\right)$ and other radiatively active gases, BVOC emissions from forests will increase, yielding more condensable products that can partition into the particle phase and cause more nucleated particles to reach sizes where they can act as cloud-condensation nuclei ( $\mathrm{CCN})$, leading to increased cloud albedo and a regional decrease in solar radiation reaching the surface (Paasonen et al., 2013). While analyses of this postulate have not fully quantified the role of new particle formation (NPF) or growth of nucleated particles by condensation of BVOC oxidation products in generation of potential $\mathrm{CCN}$, previous analyses using numerical simulations suggest $45 \%$ of global low-level cloud $\mathrm{CCN}$ at $0.2 \%$ supersaturation derive from nucleated particles (Merikanto et al., 2009). Regional-scale simulations indicate boundarylayer nucleation significantly contributes to $\mathrm{CCN}$-sized particles over eastern North America (Luo and Yu, 2011). Further, while nucleation in the free-troposphere likely makes a larger contribution to $\mathrm{CCN}$ production, observationally based estimates of survival and growth rates of nucleation particles in the planetary boundary-layer imply a non-negligible fraction reach $100 \mathrm{~nm}$ diameter within $24 \mathrm{~h}$ and thus may contribute to the CCN concentration (Pierce et al., 2014; Westervelt et al., 2013). However, the cause-effect relationships are complex, and the role of BVOC emissions remains uncertain. While monoterpene emissions and concentrations exhibit a positive correlation with NPF and growth (Paasonen et al., 2013), there is evidence of infrequent NPF over forests with high isoprene to monoterpene emission ratios (Kanawade et al., 2011) and inferences from experimental chambers indicate that - at least in some forest environments - isoprene may suppress NPF possibly via a reduction in oxidant availability (Kiendler-Scharr et al., 2009).

There is also ongoing debate regarding the degree to which BVOC are chemically processed within forest canopies and thus the degree to which BVOC oxidation products exhibit uniform or complex vertical profiles, and how those profiles vary with the hour of the day (Saylor, 2013). The degree of in-canopy processing of BVOC has importance to possible variations in particle size distribution (PSD) through the canopy (including growth of the nucleation mode particles due to phase partitioning of the BVOC oxidation prod- ucts), and to the likelihood of within canopy capture of the nucleation mode particles (since deposition velocities are a function of particle diameter, $D_{\mathrm{p}}$ ). Nucleation mode particles exhibit high deposition velocities to forest canopies due to their high Brownian diffusion velocities, the large surface area of forests and enhancement of particle capture efficiencies due to leaf micro-texture (Petroff et al., 2009). There is also evidence that nano-particles may penetrate leaves via the stomata (Burkhardt et al., 2012; Corredor et al., 2009). Actual deposition velocities (surface capture) to forests are complex functions of factors such as leaf orientation, and the key leaf characteristics (width, length and thickness) are variable by species. However, using an analogy of a filter (Lin and Khlystov, 2012), the particle collection efficiency $(E)$ is

$E=1-\exp \left(\frac{-4 \times \alpha \times E_{\mathrm{D}} \times t}{\pi \times d_{\mathrm{f}} \times(1-\alpha)}\right)$.

$\alpha=$ packing density, $t=$ thickness of the filter, $d_{\mathrm{f}}=$ fiber diameter, $E_{\mathrm{D}}=$ collection efficiency from Brownian diffusion, which is a function of $D$ (particle diffusivity) and thus $D_{\mathrm{p}}, U$ (wind speed) and $\alpha$.

Thus to the first order, as the canopy surface area (packing density and thickness) increases, the particle collection efficiency increases. Further, as $D_{\mathrm{p}}$ decreases, the collection efficiency increases. Indeed, eddy covariance flux measurements at the deciduous forest site from which measurements are presented herein (Morgan Monroe State Forest, MMSF), indicate deposition velocities of $8 \mathrm{~nm}$ diameter particles are three times higher than $30 \mathrm{~nm}$ particles, and five times higher than $80 \mathrm{~nm}$ particles (Pryor et al., 2009). The mean LAI of MMSF during the vegetation season is $4.5-4.7 \mathrm{~m}^{2} \mathrm{~m}^{-2}$ (and is non-uniform in the vertical, Fig. 1) potentially leading to high, and vertically varying, particle collection efficiency. Few direct measurements of vertical ultrafine particle gradients through forest canopies exist, but a limited number of studies have reported above and below canopy PSD that provide evidence of substantial canopy capture of ultrafine particles. For example, the mean ratio of nuclei mode (i.e., $D_{\mathrm{p}}<100 \mathrm{~nm}$ ) concentrations below to above canopy in the coniferous forest at Hyytiälä was reported to be in the range 0.85-0.90 (Huang et al., 2014). The mean ratio of below $(6 \mathrm{~m})$ to above canopy $(46 \mathrm{~m})$ number concentration ratios for $D_{\mathrm{p}}=6-30 \mathrm{~nm}$ at MMSF computed using data when nucleation events occurred during December 2006 - December 2008 is $\sim 0.7$ (Pryor et al., 2010).

Herein we present PSD $\left(D_{\mathrm{p}}: 6-520 \mathrm{~nm}\right)$ from a three-level gradient measurement system deployed in and over a deciduous forest canopy in south-central Indiana (Fig. 1). We use these measurements to investigate the role of the canopy in determining the growth of recently nucleated particles and their surface removal. Previous work at MMSF indicates NPF is focused in the nocturnal residual layer, but those particles are rapidly entrained into the growing boundary layer and brought into contact with the underlying forest (Crippa et al., 2012). Ternary nucleation $\left(\mathrm{NH}_{3}-\mathrm{H}_{2} \mathrm{SO}_{4}-\mathrm{H}_{2} \mathrm{O}\right)$ appears 
a)

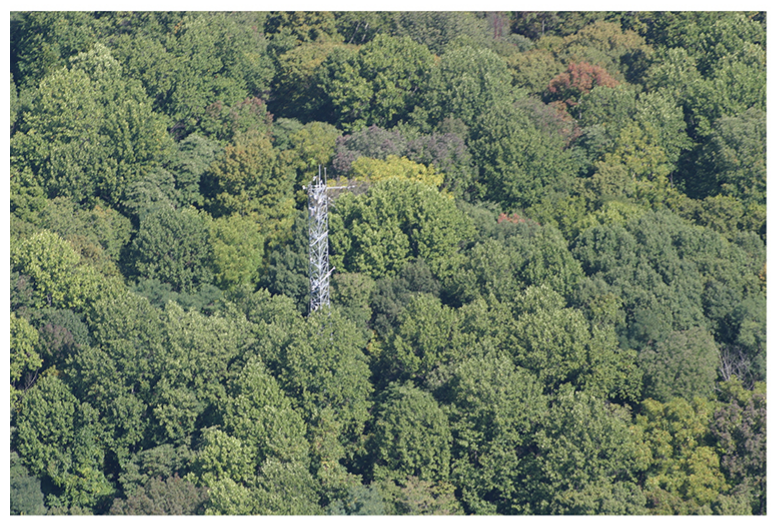

c)

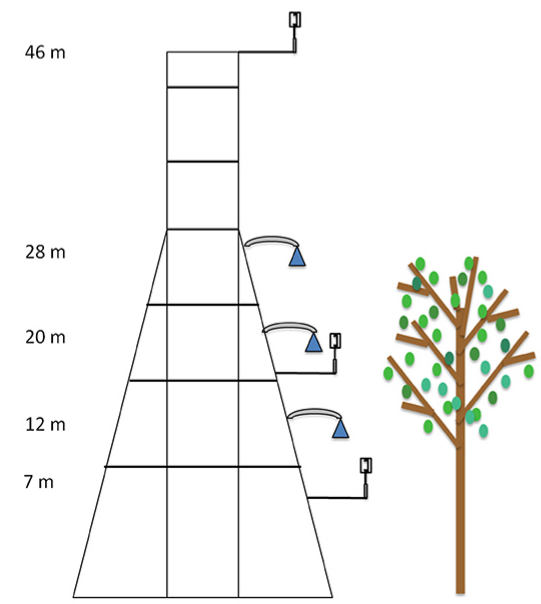

b)

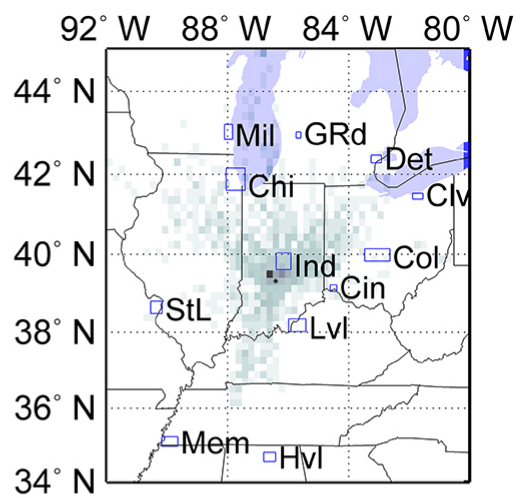

d)

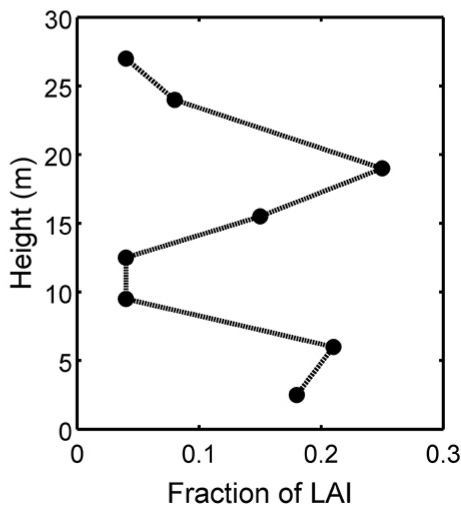

Figure 1. Overview of the measurement location and instrumentation deployed in Morgan Monroe State Forest (MMSF). (a) Photograph of the MMSF tower and surrounding canopy taken in September 2013. (b) Map showing the location of the tower site (•). The underlying shading shows the frequency with which $24 \mathrm{~h}$ back trajectories from MMSF started at the time of min(GMD) passed over a grid cell (resolution; $0.2 \times 0.2^{\circ}$ ) and were within a nominal boundary layer of $500 \mathrm{~m}$ depth (where a more intense color indicates a higher frequency). Major urban areas in the region are shown using the following three letter designations: Mil = Milwaukee; GRd $=$ Grand Rapids; Det $=$ Detroit; $\mathrm{Cle}=$ Cleveland $; \mathrm{Col}=$ Columbus; Ind $=$ Indianapolis; $\mathrm{StL}=$ Saint Louis; Mem $=$ Memphis; $\mathrm{Cin}=$ Cincinnati Lvl $=$ Louisville and $\mathrm{Hvl}$ $=$ Huntsville. (c) Schematic of the MMSF tower and the location of inlets used to sample the PSD. (d) Profile of the fraction of the total leaf area index (LAI) as a function of height.

to dominate NPF at MMSF due to the high precursor concentrations (Pryor et al., 2011), at least during spring when NPF is most commonly observed (Pryor et al., 2010). However, we postulate that some fraction of the subsequent growth of nucleation mode particles may be due to condensation of BVOC oxidation products. Indeed, data collected during 2006-2008 at this site were included in the analysis of Paasonen et al. (2013) and, like other forests' sites, concentrations of $100 \mathrm{~nm}$ particles exhibited a positive association with $T$.

PSD measurements collected at MMSF between March 2012 and March 2014 inclusive, are analyzed here in the context of the following two objectives:

1. To determine the degree to which the concentration of nucleation mode particles, their size distribution and/or their growth rates (GR) vary with the sampling height within the canopy.

2. To determine the degree to which the PSD and specifically the growth of nucleation mode particles $(6-30 \mathrm{~nm})$ is a function of canopy conditions and modeled emissions of BVOC. This objective is thus linked to understanding the degree to which the postulated negative climate feedback mechanism is robust to changes in regional climate and specifically the occurrence of drought. 


\section{Methods}

\subsection{Sampling methods}

The $46 \mathrm{~m}$ flux tower from which we present data was installed in MMSF in $1997\left(39^{\circ} 53^{\prime} \mathrm{N}, 86^{\circ} 25^{\prime} \mathrm{W}\right)$, and the canopy has subsequently grown in to virtually envelope the tower (Fig. 1a). Thus we assume the profile measurements presented herein are reasonably representative of an undisturbed canopy. MMSF extends over $97 \mathrm{~km}^{2}$ and is a secondary successional broadleaved forest. The overstory is dominated by sugar maple (Acer saccharum), tulip poplar (Liriodendron tulipifera), sassafras (Sassafras albidum), white oak (Quercus alba) and black oak (Quercus velutina), with the relative contribution of each to the basal area being $\sim 27,19,10,9$ and $9 \%$, respectively (Pryor et al., 2001). The most common understory species are pawpaw (Asimina triloba), spicebush (Lindera benzoin) and sweet cicely (Osmorhiza claytonii) (Pryor et al., 2001). Recent measurements suggest that sugar maples contribute $37 \%$ of the total LAI, with $11 \%$ of LAI from tulip poplar, $4 \%$ from sassafras, $6 \%$ from oak, and $41 \%$ from other (including subcanopy) species (Roman et al., 2014).

The PSD measurements presented herein were taken at $28 \mathrm{~m}$ (near the top of the canopy), 20 and $12 \mathrm{~m}$ (near the bottom of the overstorey) (Fig. 1c and d) using a TSI Fast Mobility Particle Sizer (FMPS 3091) (Fig. 1). Using a valve switching system, air is drawn sequentially at $17 \mathrm{lpm}$ down $8.9 \mathrm{~mm}$ inner diameter copper tubing from each sampling level. To ensure the PSD from the different sampling levels are comparable the dimensions of the three copper sampling tubes are identical. The $12 \mathrm{~m}$ level is sampled during $0-10 \mathrm{~min}$ past the hour, the $20 \mathrm{~m}$ level is sampled from $10-20 \mathrm{~min}$ past the hour, while the $28 \mathrm{~m}$ level is sampled during $20-30 \mathrm{~min}$ past the hour. This sampling pattern is then repeated such that each level is sampled for two $10 \mathrm{~min}$ periods within each hour. To avoid unstable flow during the valve switching, we use only the central $8 \mathrm{~min}$ in each $10 \mathrm{~min}$ period to derive an estimate of the PSD at each level (in 32 logarithmically spaced channels in the diameter space; 6-520 nm). The comparability of PSD measurements from the three sampling lines was evaluated at the beginning and end of the field deployment by moving the tubes to a common sampling height and sampling for 3 days. Multiple linear regression of the particle concentrations from each of the sampling lines integrated over the nucleation mode indicated variance explanation $\left(R^{2}\right)>0.94$, slopes of $1 \pm 0.12$ and intercepts of $<6 \%$ of the mean concentration. Similar analyses for the individual size channels with $D_{\mathrm{p}}<350 \mathrm{~nm}$, indicated regression slopes of $1 \pm 0.2$, intercept $<7 \%$ of the mean concentration in that size bin and $R^{2}>0.8$. The residence time in each of the sampling tubes is $7.5 \mathrm{~s}$. Empirical tubing penetration efficiencies were obtained by comparing PSD measurements conducted with flow through one of the sampling lines and without a sampling line (Fig. 2). The resulting empirical wall loss

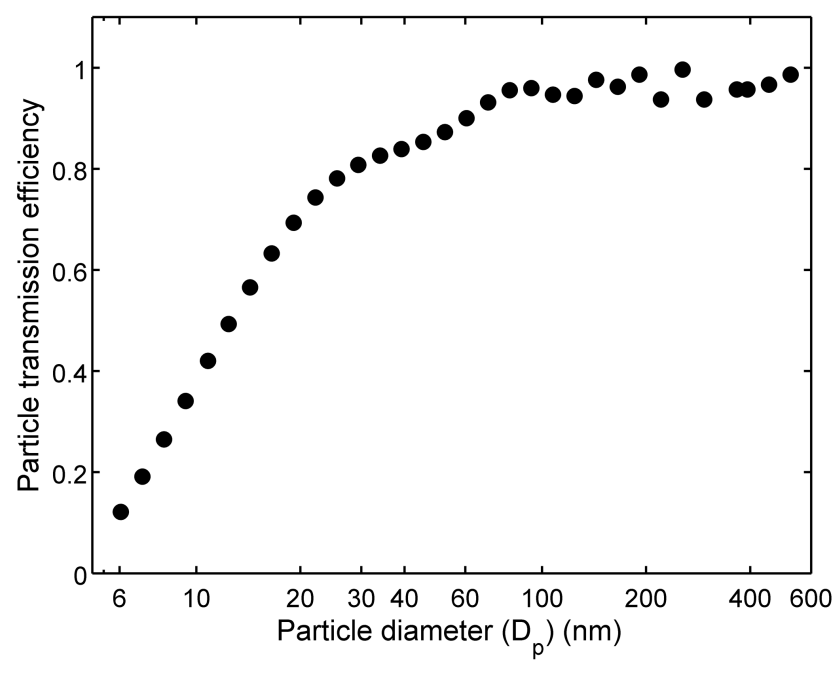

Figure 2. Empirically derived particle transmission efficiencies for the copper sampling lines used in the gradient measurements, which are used to correct the PSD measurements from all three sampling heights.

corrections are applied to all PSD measurements presented herein.

Turbulence measurements presented in this study derive from three Gill Windmaster Pro 3-D sonic anemometers deployed at 46, 20 and $7 \mathrm{~m}$. The other physical measurements presented herein are taken as part of the AmeriFlux measurement suite. The precipitation measurements derive from a Texas Electronics TE25 tipping bucket rain gauge deployed above the canopy, PAR measurements are taken using a LICOR LI-190 quantum sensor deployed at $46 \mathrm{~m}$, air temperature is measured using a Meteolabor AG VTP37 thermohygrometer at $46 \mathrm{~m}$, and LAI measurements are from a LICOR-2200, which is used to obtain measurements along three transects radiating from the tower every sixth day during the vegetation season. The soil moisture measurements derive from Campbell Scientific CS616 time-domain reflectometry (TDR) probes that measure the volumetric water content from $0 \%$ to saturation. The soil moisture data were calibrated and scaled using gravimetric samples collected weekly at the TDR monitoring locations. Net exchange of $\mathrm{C}$ (net ecosystem exchange, NEE) is the difference between photosynthetic uptake of $\mathrm{CO}_{2}$ and respiration and is derived using eddy covariance analysis of $10 \mathrm{~Hz}$ data from a Campbell Scientific CSAT3 sonic anemometer deployed at $46 \mathrm{~m}$ and a LI-COR LI-7000 gas analyzer. The $\mathrm{CO}_{2}$ fluxes are filtered to remove outliers and periods when the friction velocity $\left(u_{*}\right)<0.3 \mathrm{~m} \mathrm{~s}^{-1}$. The resulting data are used to parameterize simple models for the principal components of NEE - ecosystem gross-primary productivity (GEP) and total ecosystem respiration (RE) - which are used to gap-fill the NEE data (see details regarding carbon flux measurements at this site given in Schmid et al., 2000). 
The 2012 calendar year was characterized by widespread intense drought and anomalously high temperatures over a wide fraction of the central US, including Indiana (Mallya et al., 2013). Conditions at MMSF during the vegetation season of 2012 were considerably drier than during 2013. The annual total accumulated precipitation was $783 \mathrm{~mm}$ in 2012 vs. $1119 \mathrm{~mm}$ during 2013 (which is comparable to the 1999-2013 mean value of $1068 \mathrm{~mm}$ ) (Fig. 3b). During the peak of the 2012 growing season (June and July), the site received only about $10 \%$ (i.e., $23 \mathrm{~mm}$ ) of the long-term (1999-2011) mean rainfall ( $242 \mathrm{~mm}$ for June and July). The mean air temperature was also higher during 2012. Mean $T$ during the period when measured LAI $>3$ was $25.2^{\circ} \mathrm{C}$ in 2012 and $23.0^{\circ} \mathrm{C}$ in 2013 (Fig. 3a). The cumulative annual net ecosystem $\mathrm{C}$ uptake was only suppressed by $\sim 4 \%$ in 2012 relative to 2013 , due principally to the exceptionally early start of the vegetation season in 2012 (Fig. 3c). The prolonged rainfall deficit during the vegetation season in 2012 was associated with a substantial decrease in soil moisture availability (Fig. 3b) and reduced photosynthesis, and thus decreased net ecosystem uptake of C (Fig. 3c) (Roman et al., 2014). We therefore use these contrasting years to provide inferential information regarding how ultrafine aerosol-particle size distributions over mid-latitude deciduous forests such as MMSF might respond to changing BVOC emissions under an altered climate.

\subsection{Event definition and PSD analyses}

It is important to note that PSD collected with the FMPS detect particles formed from NPF only after substantial growth from the formation diameter ( $\leq 3 \mathrm{~nm}$ ) (Kulmala et al., 2013). Nevertheless, while these data cannot be used to characterize the nucleation process, they can be used to document that NPF has occurred and to quantify the subsequent GR. Thus the PSD from the $28 \mathrm{~m}$ sampling level were used to characterize NPF event using a subjective protocol, in which days are designated as A, B, C event types or the day is designated as a "non-event" (Dal Maso et al., 2005) (see Fig. 4). Consistent with prior analyses, back trajectories computed using the NOAA HYSPLIT4 PC based model (August 2013 release) for A-type events exhibit an omni-directional pattern (Fig. 1b), emphasizing the regional nature of NPF over eastern North America (Crippa and Pryor, 2013).

All A events, which exhibit (i) unambiguous evidence for the presence of a nucleation mode with a number geometric mean diameter $(\mathrm{nGMD})<16 \mathrm{~nm}$, and (ii) clear and sustained growth and which occurred during rain-free periods, were selected for detailed analyses (see examples of PSD at the three levels given in Fig. 5). Data from each sampling level are used to determine the minimum nucleation mode number geometric mean diameter (min(nGMD)) and number concentrations (integrated over the size channels, that have a sizing channel mean diameter $\left.\left(D_{\mathrm{p}}\right)=6.04-29.4 \mathrm{~nm}\right)$. These data are also used to compute nucleation mode GR for each level for the first $3 \mathrm{~h}$ after the $\min (\mathrm{nGMD})$, and for the subsequent 3 hours (i.e., hours 3-6 after min(nGMD)).

\subsection{BVOC emission estimation}

Hourly emissions of isoprene, monoterpenes and sesquiterpenes are calculated for all days on which A-class NPF events were observed during the vegetation season (defined here as days with LAI > 3). The emissions were summed over the $3 \mathrm{~h}$ prior to $\min (\mathrm{nGMD})$ in the nucleation mode and $1 \mathrm{~h}$ subsequent to $\min (\mathrm{nGMD})$ using day-specific LAI and hourly measurements of air temperature and PAR. The emission factors are taken from the PCBEIS component of the MEGAN emissions model (Guenther et al., 2012), and the emissions are computed using the forest composition data given above for the five dominant tree species with the remaining $26 \%$ allocated as "mixed broadleaved forest." The relationship between cumulative BVOC emission and GR of the nucleation mode are assessed using both Pearson $(r)$ and Spearman (ranked) $(\rho)$ correlation coefficients, where the latter is used to quantify the importance of outliers in determining the correlation.

\section{Results and discussion}

PSD data from MMSF collected during 2006-2008 indicated NPF on $\sim 46 \%$ of classifiable days and that $18 \%$ of classifiable days exhibited A class events (Pryor et al., 2010). Data for March 2012-March 2014 indicate evidence of NPF on $55 \%$ of classifiable days, and $27 \%$ of classifiable days exhibited A-type events (Fig. 4). The frequency of NPF at MMSF is similar to that reported for Egbert in Ontario (downwind of Toronto) (Crippa and Pryor, 2013), but is higher than was reported in data collected at a forest in Michigan during 1 July-3 August 2009, which indicated clear evidence for intense NPF on only 2 days (Kanawade et al., 2011). NPF at MMSF is likely enhanced by the relatively large local emissions of ammonia and frequent impact of air masses with high sulfuric acid concentrations (Pryor et al., 2011).

Examples of PSD measurements at the three sampling heights during days with A-class NPF events are given in Fig. 5. Data from 29 March 2012 (Fig. 5a) are representative of those collected during the period of rapidly increasing LAI at MMSF (and specifically marked "greening" of the lower canopy and understorey). During this NPF event the maximum nucleation mode concentrations at 28 and $20 \mathrm{~m}$ sampling heights were within $3 \%$ of each other, while the maximum nucleation mode concentration at $12 \mathrm{~m}$ was $<60 \%$ of that at $28 \mathrm{~m}$. The $\min (\mathrm{nGMD})$ at $12 \mathrm{~m}$ was also $2 \mathrm{~nm}$ larger than at 20 or $28 \mathrm{~m}$. By 23 April 2012 (Fig. 5b), the overstorey LAI had increased to $>3$. The NPF event on this day exhibited equal $\min (\mathrm{nGMD}$ ) (to within $1 \mathrm{~nm}$ ) at the three sampling heights. Data from the $20 \mathrm{~m}$ height exhibited highest maximum nucleation mode number concentrations $(5 \%$ higher 

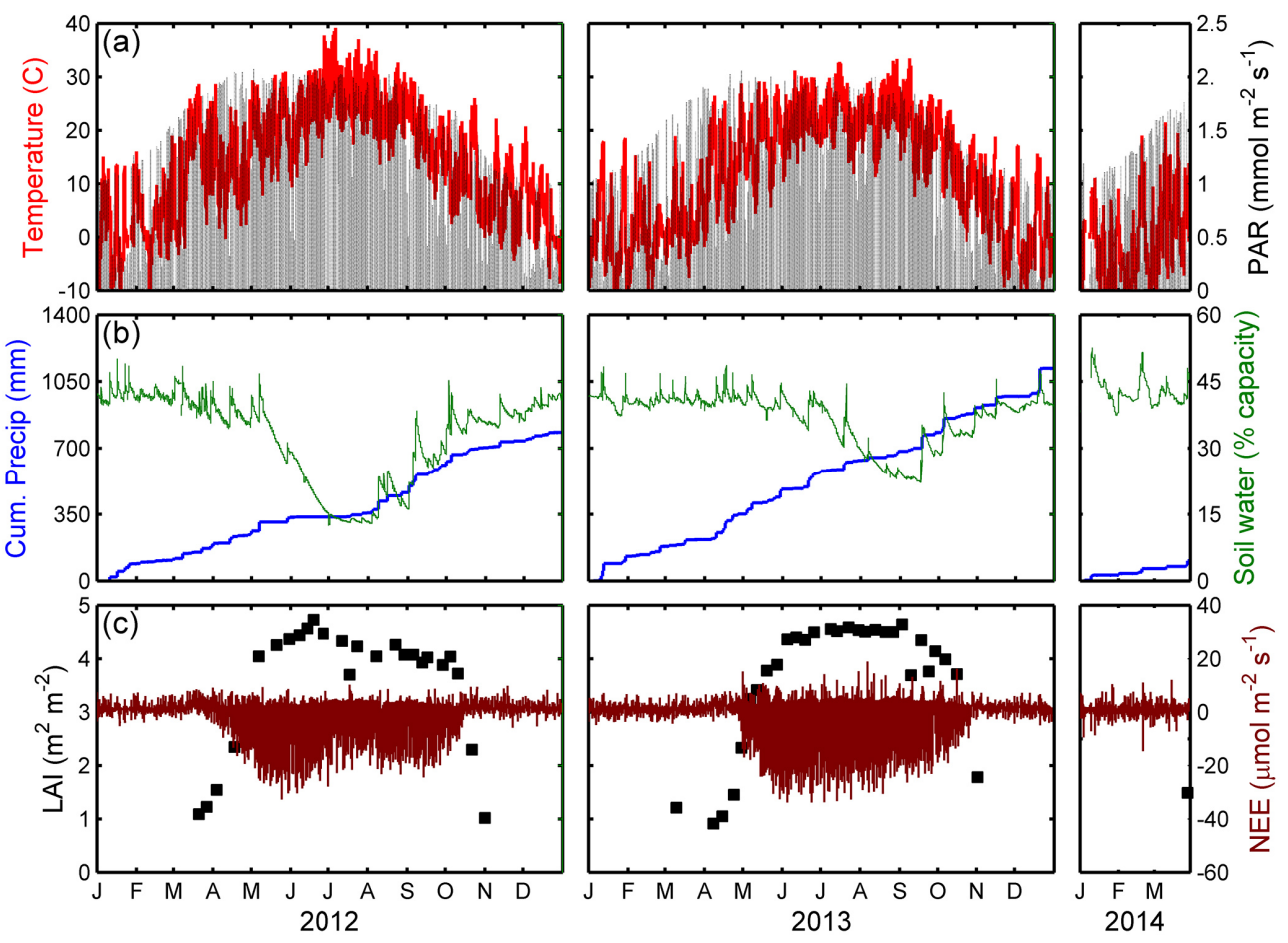

Figure 3. Overview of conditions at MMSF during 2012 to March 2014. (a) Hourly average air temperature (at $46 \mathrm{~m})\left({ }^{\circ} \mathrm{C}\right)$ and photosynthetically active radiation (PAR) $\left(\mathrm{mmol} \mathrm{m}^{-2} \mathrm{~s}^{-1}\right)$. (b) Cumulative precipitation (Cum. Precip) (mm) by year, day, and daily soil water (\% capacity). (c) Mean leaf area index (LAI) during the vegetation system derived from measurements along three transects radiating from the tower along with the hourly net ecosystem exchange (NEE) $\left(\mu \mathrm{mol} \mathrm{m} \mathrm{m}^{-2} \mathrm{~s}^{-1}\right)$.

than at $28 \mathrm{~m}$ ) but the $12 \mathrm{~m}$ height exhibited only 0.8 times the maximum nucleation mode number concentration as measured at $20 \mathrm{~m}$. By 12 October 2012 (Fig. 5c), NEE was beginning to decline although LAI was $\sim 3$, and PSD measurements from this day are representative of many (but not all) events that occurred during the leaf-off period, with virtually no gradient in maximum concentration or min(nGMD).

Consistent with these case studies, the data ensemble indicates nucleation mode number concentrations are typically lower at the $12 \mathrm{~m}$ sampling height than at either the 20 or $28 \mathrm{~m}$ level (Fig. 6a). On average the maximum nucleation mode number concentration measured at the $12 \mathrm{~m}$ level during A class events is $84 \%$ of the maximum concentration observed at any of the three sampling levels. The mean ratio of maximum nucleation mode number concentration at 20 to that at $28 \mathrm{~m}$ is $94 \%$. This might be interpreted as indicating removal of, on average, $16 \%$ of the nucleation mode particles by the entire canopy (i.e., all leaves between 28 and $12 \mathrm{~m}$ ), and that the upper canopy (i.e., leaves between 28 and $20 \mathrm{~m}$ ) removes an average of $6 \%$ of nucleation mode particles. The highest nucleation mode number concentration was observed at the $12 \mathrm{~m}$ level on only 16 of the 105 events, while 57 of the events exhibited the highest concentration at $28 \mathrm{~m}$ and 32 of the events exhibited the highest concentration at $20 \mathrm{~m}$. The FMPS has only 12 channels in the $6-30 \mathrm{~nm}$ diameter range leading to some uncertainty in the characterization of both the nGMD and GR. Nevertheless, the nGMD was also generally higher at the lowest sampling level, possibly as a result of preferential in-canopy removal of the smallest particles and growth by both coagulation and partitioning of semi-volatile compounds during vertical transport. These observations are thus consistent with an elevated source of the nucleation mode particles, efficient vertical transport, and limited particle removal in the comparatively sparse upper canopy, but also greater removal in the denser lower portion of the canopy (see LAI profile in Fig. 1d). However, the vertical profiles of nucleation mode particles must be interpreted with caution due to the relatively large corrections for transmission efficiency (Fig. 2), and possible complications resulting from growth of sub- $6 \mathrm{~nm}$ particles into the detectable size range of the FMPS during transport to, and through, the canopy.

Consistent with prior analyses at this site, the NPF class A events typically commenced during the transition towards unstable conditions during the day (Pryor et al., 2010). The min(nGMD) was typically associated with positive kinematic heat flux from the canopy (as measured at $46 \mathrm{~m}$ ) (Fig. 6b), during destabilization of the boundary layer (Crippa et al., 2012). NPF is promoted under high actinic flux (Boy and Kulmala, 2002), so the relatively high frequency of NPF events in data from MMSF collected during 2012 (Fig. 4) may be partially attributable atypically low fre- 


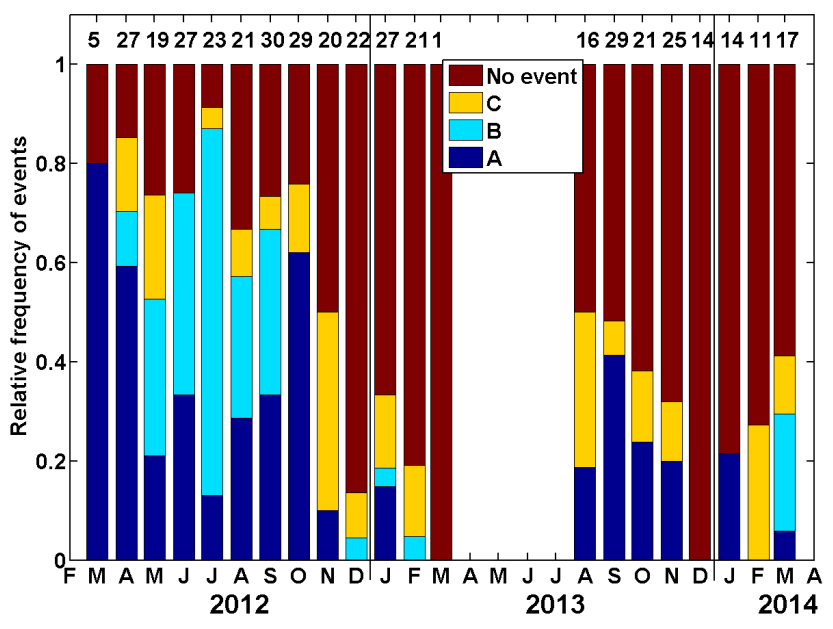

Figure 4. Overview of the occurrence of new particle formation (NPF) and nucleation event type (A, B or C event, or non-event) by month. The number at the top of the frame indicates the number of days on which data were collected and during which no instrument fault was report and no instrument maintenance was performed. The classification into event type (per the classification protocol reported in Dal Maso et al., 2005) was undertaken by a single person. Thus, while the classification is subjective, it should be consistent across the study period. Note the FMPS was not operated at the site during April-July 2013, inclusive, and thus no data are presented for that period.

quency of occurrence of cloud cover and high net radiation flux during that year.

The hourly average above- and below-canopy kinematic heat fluxes did not indicate full coupling during the hour in which the min(nGMD) was observed (Fig. 6b). Indeed, conditions below the canopy were frequently characterized by small magnitude negative heat flux. Nevertheless, the occurrence of the $\min (\mathrm{nGMD})$ and the maximum rate of change of nucleation mode concentrations $(\max (\mathrm{d} N / \mathrm{d} t))$ during class A events is typically simultaneous at all three sampling heights within the sampling interval of $30 \mathrm{~min}$ (Fig. 6d).

The mean nucleation mode GR computed for the three sampling heights over the $3 \mathrm{~h}$ period after the min(nGMD) are statistically indistinguishable, at least within the measurement uncertainty due to the relatively coarse resolution of the FMPS particle sizing (Fig. 6c). This is consistent with the time scale for vertical mixing of a passive tracer derived from the ratio of sampling height $(z)$ to $u_{*}$ of $\leq 300 \mathrm{~s}$. Multiple linear regression fits to GR from the three heights during the $105 \mathrm{~A}$-class events indicate variance explanation $\left(r^{2}\right.$ values) of 0.71 to 0.82 , small intercept values $\left(\sim 0.15 \mathrm{~nm} \mathrm{~h}^{-1}\right)$ and regression slopes of $>0.8$. This implies the compounds responsible for the majority of the growth of nucleation mode particles are relatively well mixed in the vertical.

The mean GR of the nucleation mode particles measured at $20 \mathrm{~m}$ is $\sim 2 \mathrm{~nm} \mathrm{~h}^{-1}$ (Fig. 6a), which is broadly consistent with, but slightly lower than, the mean GR at $46 \mathrm{~m}$ at this site observed in data from 2006 to $2008\left(\sim 2.5 \mathrm{~nm} \mathrm{~h}^{-1}\right)$. This difference may be due to the different instrumentation (a nanoSMPS from TSI was used for the PSD measurements in the prior study). However, it may reflect physical processes. For example, the difference may indicate that canopy removal of smaller particles played a greater role in the within canopy observations presented here, relative to the prior measurements that were taken well above the canopy. The difference may also reflect slower particle growth due to relatively low concentrations of oxidation products of BVOC during the 2012 drought. The latter explanation is supported by the large difference in GR computed for the end of the growing season events in 2012 vs. 2013 (Fig. 7b). The mean GR for events during the month of September in 2012 is $1.2 \mathrm{~nm} \mathrm{~h}^{-1}$ while that for September 2013 is $2.9 \mathrm{~nm} \mathrm{~h}^{-1}$ (there were 10 events in September 2012 and 11 in September 2013). Furthermore, the lowest GR during the vegetation season of 2012 were observed during July (Fig. 7a) when NEE was also greatly suppressed (Fig. 3c).

In light of the differences in GR computed for the vegetation seasons of 2012 and 2013, an analysis was undertaken to assess whether the $3 \mathrm{~h}$ GR exhibited a different dependence on modeled BVOC emissions from MEGAN-PCBEIS during these two seasons. We postulate that reduced BVOC emissions during 2012 due to the drought may have led to lower production of semi-volatile BVOC oxidation products and that thus contributed to the reduced GR of nucleation mode particles. Recall that the modeled BVOC emissions are solely a function of the base rate (which is a function of tree species), air temperature and PAR (for isoprene emissions only). Thus, although plant physiology suggests longterm exposure to drought and extreme heat suppresses BVOC emissions (Niinemets, 2010), the modeled BVOC emissions are invariant with soil water availability. The statistical association between modeled BVOC emissions and observed nucleation mode GR appears to differ between these 2 years (Fig. 7c and Table 1). Specifically, there is a significant correlation between GR of 6-30 nm mode particles and modeled monoterpene and sesquiterpene emissions in 2013, but not in 2012. Thus the drought of 2012 may have been sufficient to suppress actual monoterpene and sesquiterpene emissions relative to the modeled values and therefore the modeled BVOC emissions are not reflective of the availability of condensable products during 2012.

Following evidence that partitioning of semi-volatile BVOC-oxidation products may be more important in the later growth of the nucleation mode (i.e., only after the initial growth to diameters $\sim 15 \mathrm{~nm}$ has been achieved) (Bzdek et al., 2012; Stolzenburg et al., 2005), an additional analysis was undertaken in which the $3 \mathrm{~h}$ GR after nGMD $\sim 15 \mathrm{~nm}$ was correlated with modeled BVOC emissions. The results are qualitatively similar to those shown in Table 1 . The Pearson correlation coefficients $(r)$ between the GR and both total modeled monoterpene and sesquiterpene emissions are $<0.13$ for the vegetation season of 2012 and $>0.40$ in data 
(a)
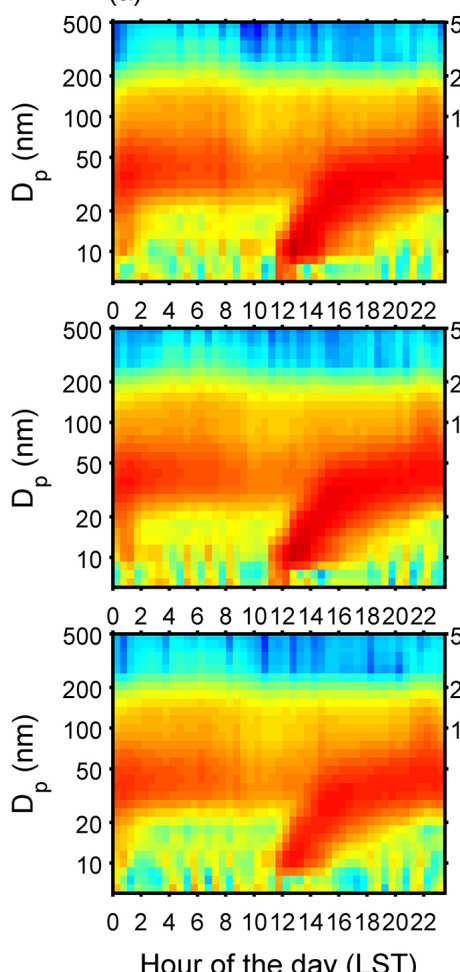

(b)

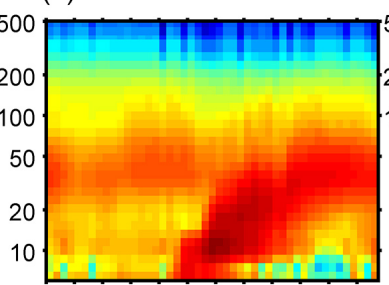

0246810121416182022

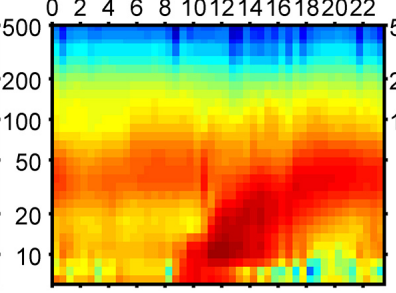

0246810121416182022

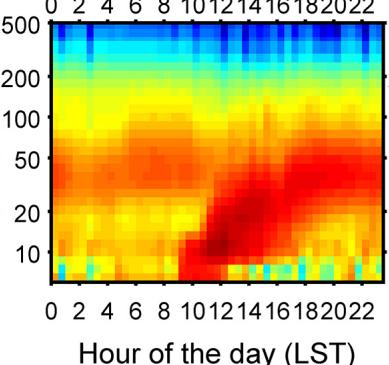

(c)
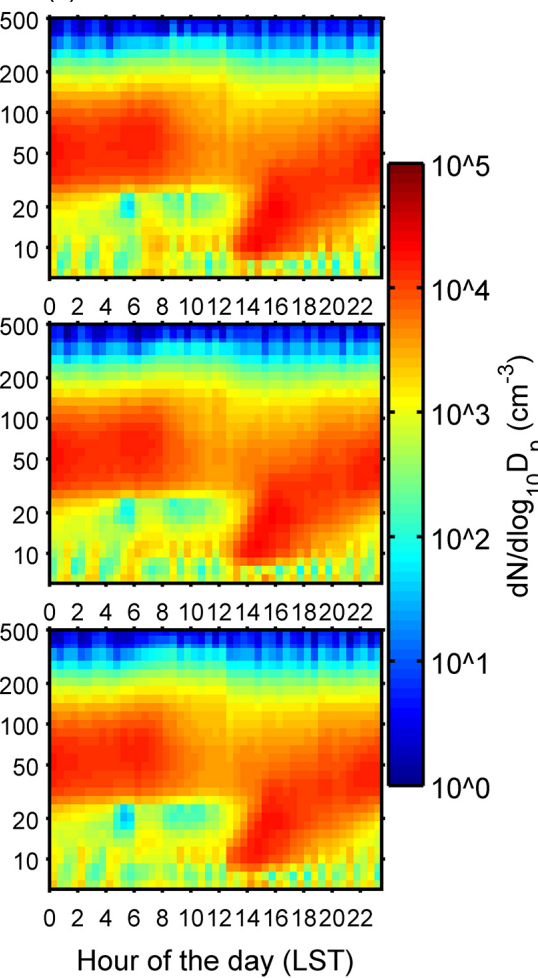

Figure 5. Measured particle size distributions (corrected for tubing losses) at the three sampling heights: the upper panels show measurements from $28 \mathrm{~m}$, the middle panels depict data from $20 \mathrm{~m}$, and the lower panels show data from $12 \mathrm{~m}$ for (a) 29 March 2012 , (b) 23 April 2012 and (c) 12 October 2012. The data are shown as the average of $10 \mathrm{~min}$ of measurements at each height during each half-hour.

Table 1. Correlation coefficients (Spearman ranked correlation $(\rho)$ and Pearson correlation $(r)$ ) for GR (at $20 \mathrm{~m}$ ) in the $3 \mathrm{~h}$ after the minimum geometric mean diameter (GMD) was observed and total modeled BVOC emissions for the $3 \mathrm{~h}$ prior to the min(GMD) and $1 \mathrm{~h}$ subsequent to the $\min (\mathrm{GMD})$ for all events recorded during the active vegetation season (defined here as LAI > 3). Note the correlation coefficients with GR from the other three measurement heights are indistinguishable from those reported for $20 \mathrm{~m}$ in the table. Note the instrument was not operated at the site during April-July 2013, inclusive leading to the lower number of observed NPF events during the 2013 vegetation period.

\begin{tabular}{lrr|rr}
\hline $\begin{array}{l}\text { Year (sample } \\
\text { size, \# events } \\
\text { during the veg- } \\
\text { etative season } \\
\text { whenLAI }>\text { 3) }\end{array}$ & $2012(43)$ & 2013 (16) \\
\hline & Spearman $\rho$ (probability $\rho$ & Pearson $r$ (probability $r$ & Spearman $\rho$ (probability $\rho$ & Pearson $r$ (probability $r$ \\
& is not different to 0) & is not different to 0) & is not different to 0) \\
\hline Isoprene & $0.01(0.94)$ & $-0.04(0.79)$ & $0.23(0.35)$ & $0.44(0.07)$ \\
Monoterpenes & $-0.06(0.72)$ & $-0.08(0.58)$ & $0.44(0.07)$ & $0.37(0.13)$ \\
Sesquiterpenes & $-0.05(0.73)$ & $-0.09(0.57)$ & & $0.33(0.18)$ \\
\hline
\end{tabular}

from 2013. Similar results are also found when the forest composition is varied to reflect the contributions of the different trees species to LAI (and not basal area as above). GR and both total monoterpene and sesquiterpene emissions exhibit $r=-0.09$ in the vegetation season of 2012 and 0.37 and 0.33 , respectively in 2013 . Thus the inference that the relationship between nucleation mode GR and modeled BVOC emissions differed in the 2 years appears to be robust to variations in the assumptions regarding the precise contributions of each tree species to the canopy and the starting point of the GR calculations. 

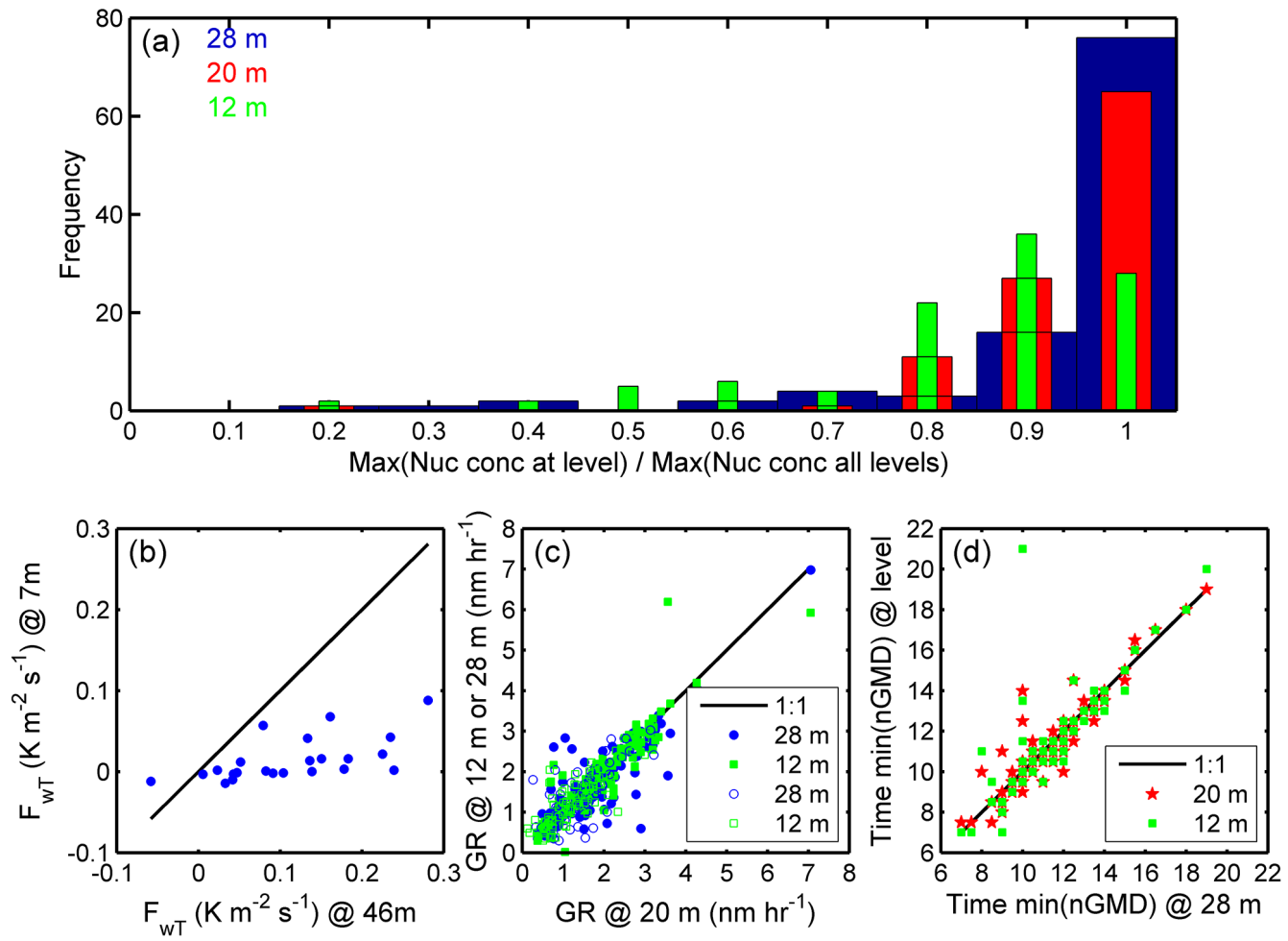

Figure 6. (a) Probability distribution of the ratio of the maximum concentration of nucleation mode particles at each height (28, 20 and $12 \mathrm{~m}$ ) to the maximum concentration at any height during each of the 105 A-type NPF events. (b) Hourly average kinematic heat flux above and below the canopy during the hour of $\min (\mathrm{nGMD})$ at $28 \mathrm{~m}$ for all events during the 2013 vegetation season. (c) Scatterplot of growth rates (GR) at 12 and $28 \mathrm{~m}$ vs. the GR at $20 \mathrm{~m}$ in the $3 \mathrm{~h}$ following the min(nGMD) (closed symbols) and 3-6h following min(nGMD) (open symbols). (d) Scatterplot of the time of day (in $30 \mathrm{~min}$ intervals) at which the min(nGMD) was observed at the three measurement heights.

\section{Concluding remarks}

New particle formation is an important source of climate relevant aerosol particles and biogenic VOC emissions from forests have been identified as playing a key role in the growth of nucleated particles to climate relevant sizes. However, uncertainty remains regarding how important BVOC are to particle growth, how BVOC emissions might alter in the future, and what fraction of nucleation mode particles are removed by forest canopies and thus play no role in regional climate forcing.

Consistent with prior research (Crippa and Pryor, 2013; Pryor et al., 2010), data collected during 2012-2014 over a deciduous forest in southern Indiana exhibit evidence of frequent NPF events (Fig. 4). Resulting nucleation mode particle concentrations are typically higher in the upper canopy and exhibit comparatively high surface capture efficiencies through the lower denser portion of the canopy (Figs. 1d and 6a), re-emphasizing the importance of forests in the removal of aerosol particles, and particularly ultrafine particles. Importantly in terms of evaluating and formulating canopy models, GR of nucleation mode particles do not appear to vary with height through the canopy (Fig. 6c), indicating that the compounds contributing to the growth of nucleation mode particles are relatively well-mixed in the vertical.

In this deciduous forest, GR of nucleation mode particles were suppressed during a drought year vs. a non-drought year in a manner consistent with reduced availability of semivolatile oxidation products from BVOC as a result of reduced photosynthetic activity. Sugar maples are the dominant overstory species in MMSF in terms of both basal area and LAI, and are increasingly the dominant late-successional species in many forests within the Midwestern USA (Abrams, 2003). Sugar maples exhibit considerably higher monoterpene emissions than the other dominant overstory species in MMSF (Geron et al., 2000), but are relatively drought intolerant (Payette et al., 1996). Indeed, leaf- and stand-level measurements in MMSF indicate sugar maples exhibited substantially lower total wood biomass $\mathrm{C}$ production $(44 \%$ reduction) in the 2012 drought year than in 2013 (Roman et al., 2014). Given that climate projections for the Midwest indicate a tendency towards both hotter and drier summers (Pryor et al., 2013), this research thus indicates that drought-induced limits on BVOC emissions from forests may limit the effectiveness of the postulated organic aerosol - negative climate feedback mechanism (Paasonen et al., 2013). 

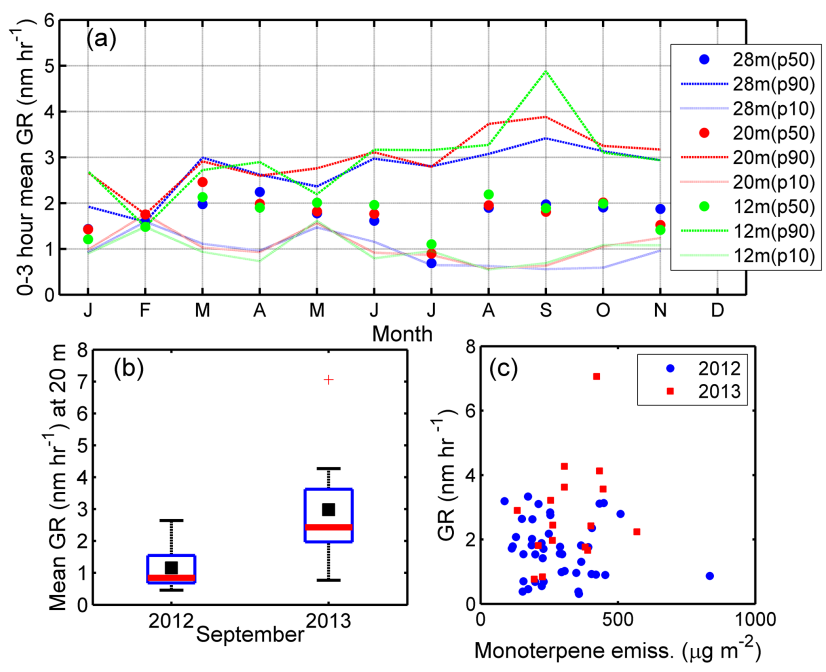

Figure 7. Summary of $3 \mathrm{~h}$ average growth rates (GR) at the three sampling levels $(28,20$ and $12 \mathrm{~m}$ ) during A-type NPF events. (a) Median, 10th and 90th percentile growth rates (GR) for the $3 \mathrm{~h}$ after the minimum number geometric mean diameter (min(nGMD)) at the three measurement heights by calendar month. Note the instrument was not operated at the site during April-July 2013 inclusive, thus the data shown for May, June and July are reflective of conditions during 2012 only. (b) Box plots of $3 \mathrm{~h}$ average GR for events during September 2012 and September 2013 (where the solid black square denotes the mean value). (c) Mean GR at $20 \mathrm{~m}$ in the $3 \mathrm{~h}$ after the nucleation mode $\min (\mathrm{nGMD}) \mathrm{vs}$. the cumulative monoterpene emissions for the $3 \mathrm{~h}$ preceding the $\min (\mathrm{nGMD})$ and the hour after $\min (\mathrm{nGMD})$, during events that occurred in 2012 and 2013 when the LAI > 3.

Author contributions. S. C. Pryor conceived of and designed the study, did the majority of the data analyses, generated the figures and wrote the majority of the manuscript. K. E. Hornsby conducted the majority of the field measurements. K. E. Hornsby and K. A. Novick contributed to the data analysis and writing.

Acknowledgements. The research presented herein was supported by a grant to SCP from NSF (1102309). The AmeriFlux data used herein (available at: http://ameriflux.ornl.gov/) were collected under funding from the Office of Science, US Department of Energy, and from the AmeriFlux Management Project, Lawrence Berkeley National Laboratory. The authors express thanks to R. Phillips, T. Roman, S. Scott and R. Sullivan of Indiana University for their assistance with data collection and processing, and R. J. Barthelmie, Cornell University for useful discussions. The authors also gratefully acknowledge assistance with BVOC emissions from G. Pouliot, EPA, K. Hansen, Roskilde University for the canopy photograph, and A. Oliphant, San Francisco State University for the LAI profile. The comments of two reviewers substantially improved the clarity of this manuscript.

Edited by: F. Yu

\section{References}

Abrams, M. D.: Where Has All the White Oak Gone?, BioScience, 53, 927-939, 2003.

Barthelmie, R. J. and Pryor, S. C.: A model mechanism to describe oxidation of monoterpenes leading to secondary organic aerosol 1. $\alpha$-pinene and $\beta$-pinene, J. Geophys. Res., 104, 23657-23699, 1999.

Boy, M. and Kulmala, M.: Nucleation events in the continental boundary layer: Influence of physical and meteorological parameters, Atmos. Chem. Phys., 2, 1-16, doi:10.5194/acp-2-1-2002, 2002.

Burkhardt, J., Basi, S., Pariyar, S., and Hunsche, M.: Stomatal penetration by aqueous solutions - an update involving leaf surface particles, New Phytol., 196, 774-787, 2012.

Bzdek, B. R., Zordan, C. A., Pennington, M. R., Luther, G. W., and Johnston, M. V.: Quantitative Assessment of the Sulfuric Acid Contribution to New Particle Growth, Environ. Sci. Technol., 46, 4365-4373, 2012.

Corredor, E., Testillano, P., Coronado, M.-J., González-Melendi, P., Fernández-Pacheco, R., Marquina, C., Ibarra, M., de la Fuente, J., Rubiales, D., Pérez-de-Luque, A., and Risueño, M.C.: Nanoparticle penetration and transport in living pumpkin plants: in situ subcellular identification, BMC Plant Biol., 9, 1-11, 2009.

Crippa, P. and Pryor, S. C.: Spatial and temporal scales of new particle formation events in eastern North America, Atmos. Environ., 75, 257-264, 2013.

Crippa, P., Petäjä, T., Korhonen, H., El Afandi, G. S., and Pryor, S. C.: Evidence of an elevated source of nucleation based on model simulations and data from the NIFTy experiment, Atmos. Chem. Phys., 12, 8021-8036, doi:10.5194/acp-12-8021-2012, 2012.

Dal Maso, M., Kulmala, M., Riipinen, I., Wagner, R., Hussein, T., Aalto, P. P., and Lehtinen, K. E. J.: Formation and growth of fresh atmospheric aerosols: eight years of aerosol size distribution data from SMEAR II, Hyytiala, Finland, Boreal Environ. Res., 10, 323-336, 2005.

Geron, C., Rasmussen, R., Arnts, R. R., and Guenther, A.: A review and synthesis of monoterpene speciation from forests in the United States, Atmos. Environ., 34, 1761-1781, 2000.

Guenther, A. B., Monson, R. K., and Fall, R.: Isoprene and monoterpene emission rate variability - Observations with Eucalyptus and emission rate algorithm development, J. Geophys. Res.Atmos., 96, 10799-10808, 1991.

Guenther, A. B., Zimmerman, P., Harley, P., Monson, R., and Fall, R.: Isoprene and monoterpene emission rate variability: model evaluations and sensitivity analyses, J. Geophys. Res.-Atmos., 98, 12609-12617, 1993.

Guenther, A., Karl, T., Harley, P., Wiedinmyer, C., Palmer, P. I., and Geron, C.: Estimates of global terrestrial isoprene emissions using MEGAN (Model of Emissions of Gases and Aerosols from Nature), Atmos. Chem. Phys., 6, 3181-3210, doi:10.5194/acp-63181-2006, 2006.

Guenther, A. B., Jiang, X., Heald, C. L., Sakulyanontvittaya, T., Duhl, T., Emmons, L. K., and Wang, X.: The Model of Emissions of Gases and Aerosols from Nature version 2.1 (MEGAN2.1): an extended and updated framework for modeling biogenic emissions, Geosci. Model Dev., 5, 1471-1492, doi:10.5194/gmd-51471-2012, 2012. 
Hallquist, M., Wenger, J. C., Baltensperger, U., Rudich, Y., Simpson, D., Claeys, M., Dommen, J., Donahue, N. M., George, C., Goldstein, A. H., Hamilton, J. F., Herrmann, H., Hoffmann, T., Iinuma, Y., Jang, M., Jenkin, M. E., Jimenez, J. L., Kiendler-Scharr, A., Maenhaut, W., McFiggans, G., Mentel, Th. F., Monod, A., Prévôt, A. S. H., Seinfeld, J. H., Surratt, J. D., Szmigielski, R., and Wildt, J.: The formation, properties and impact of secondary organic aerosol: current and emerging issues, Atmos. Chem. Phys., 9, 5155-5236, doi:10.5194/acp-9-51552009, 2009.

Huang, C.-W., Launiainen, S., Grönholm, T., and Katul, G. G.: Particle deposition to forests: An alternative to K-theory, Atmos. Environ., 94, 593-605, 2014.

Iinuma, Y., Kahnt, A., Mutzel, A., Boge, O., and Herrmann, H.: Ozone-Driven Secondary Organic Aerosol Production Chain, Environ. Sci. Technol., 47, 3639-3647, 2013.

Kanawade, V. P., Jobson, B. T., Guenther, A. B., Erupe, M. E., Pressley, S. N., Tripathi, S. N., and Lee, S.-H.: Isoprene suppression of new particle formation in a mixed deciduous forest, Atmos. Chem. Phys., 11, 6013-6027, doi:10.5194/acp-11-60132011, 2011.

Kesselmeier, J., Ciccioli, P., Kuhn, U., Stefani, P., Biesenthal, T., Rottenberger, S., Wolf, A., Vitullo, M., Valentini, R., Nobre, A., Kabat, P., and Andreae, M. O.: Volatile organic compound emissions in relation to plant carbon fixation and the terrestrial carbon budget, Global Biogeochem. Cy., 16, 1126, doi:10.1029/2001GB001813, 2002.

Kiendler-Scharr, A., Wildt, J., Dal Maso, M., Hohaus, T., Kleist, E., Mentel, T. F., Tillmann, R., Uerlings, R., Schurr, U., and Wahner, A.: New particle formation in forests inhibited by isoprene emissions, Nature, 461, 381-384, 2009.

Kulmala, M., Suni, T., Lehtinen, K. E. J., Dal Maso, M., Boy, M., Reissell, A., Rannik, Ü., Aalto, P., Keronen, P., Hakola, H., Bäck, J., Hoffmann, T., Vesala, T., and Hari, P.: A new feedback mechanism linking forests, aerosols, and climate, Atmos. Chem. Phys., 4, 557-562, doi:10.5194/acp-4-557-2004, 2004.

Kulmala, M., Kontkanen, J., Junninen, H., Lehtipalo, K., Manninen, H. E., Nieminen, T., Petaja, T., Sipila, M., Schobesberger, S., Rantala, P., Franchin, A., Jokinen, T., Jarvinen, E., Aijala, M., Kangasluoma, J., Hakala, J., Aalto, P. P., Paasonen, P., Mikkila, J., Vanhanen, J., Aalto, J., Hakola, H., Makkonen, U., Ruuskanen, T., Mauldin III, R. L.,, Duplissy, J., Vehkamaki, H., Back, J., Kortelainen, A., Riipinen, I., Kurten, T., Johnston, M. V., Smith, J. N., Ehn, M., Mentel, T. F., Lehtinen, K. E. J., Laaksonen, A., Kerminen, V.-M., and Worsnop, D. R.: Direct Observations of Atmospheric Aerosol Nucleation, Science, 339, 943-946, 2013.

Leaitch, W. R., Macdonald, A. M., Brickell, P. C., Liggio, J., Sjostedt, S. J., Vlasenko, A., Bottenheim, J. W., Huang, L., Li, S.M., Liu, P. S. K., Toom-Sauntry, D., Hayden, K. A., Sharma, S., Shantz, N. C., Wiebe, H. A., Zhang, W., Abbatt, J. P. D., Slowik, J. G., Chang, R. Y. W., Russell, L. M., Schwartz, R. E., Takahama, S., Jayne, J. T., and Nga Lee, N.: Temperature response of the submicron organic aerosol from temperate forests, Atmos. Environ., 45, 6696-6704, 2011.

Lin, M.-Y. and Khlystov, A.: Investigation of Ultrafine Particle Deposition to Vegetation Branches in a Wind Tunnel, Aerosol Sci. Tech., 46, 465-472, 2012.

Luo, G. and Yu, F.: Simulation of particle formation and number concentration over the Eastern United States with the WRF-
Chem + APM model, Atmos. Chem. Phys., 11, 11521-11533, doi:10.5194/acp-11-11521-2011, 2011.

Mallya, G., Zhao, L., Song, X. C., Niyogi, D., and Govindaraju, R. S.: 2012 Midwest Drought in the United States, J. Hydrol. Eng., 18, 737-745, 2013.

Merikanto, J., Spracklen, D. V., Mann, G. W., Pickering, S. J., and Carslaw, K. S.: Impact of nucleation on global CCN, Atmos. Chem. Phys., 9, 8601-8616, doi:10.5194/acp-9-8601-2009, 2009.

Niinemets, U.: Mild versus severe stress and BVOCs: thresholds, priming and consequences, Trends Plant Sci., 15, 145-153, 2010.

Paasonen, P., Asmi, A., Petaja, T., Kajos, M. K., Aijala, M., Junninen, H., Holst, T., Abbatt, J. P. D., Arneth, A., Birmili, W., van der Gon, H. D., Hamed, A., Hoffer, A., Laakso, L., Laaksonen, A., Leaitch, W. R., Plass-Duelmer, C., Pryor, S. C., Raisanen, P., Swietlicki, E., Wiedensohler, A., Worsnop, D. R., Kerminen, V.-M., and Kulmala, M.: Warming-induced increase in aerosol number concentration likely to moderate climate change, Nat. Geosci., 6, 438-442, 2013.

Payette, S., Fortin, M.-J., and Morneau, C.: The recent sugar maple decline in southern Quebec: probable causes deduced from tree rings, Can. J. Forest Res., 26, 1069-1078, 1996.

Petroff, A., Zhang, L., Pryor, S. C., and Belot, Y.: An extended dry deposition model for aerosols onto broadleaf canopies, J. Aerosol Sci., 40, 218-240, 2009.

Pierce, J. R., Westervelt, D. M., Atwood, S. A., Barnes, E. A., and Leaitch, W. R.: New-particle formation, growth and climaterelevant particle production in Egbert, Canada: analysis from 1 year of size-distribution observations, Atmos. Chem. Phys., 14, 8647-8663, doi:10.5194/acp-14-8647-2014, 2014.

Pryor, S. C., Barthelmie, R. J., Carreiro, M., Davis, M., Hartley, A., Jensen, B., Oliphant, A., Randolph, J., and Schoof, J.: Nitrogen deposition to and cycling in a deciduous forest, TheScientificWorld, 1, 245-254, 2001.

Pryor, S. C., Barthelmie, R. J., Spaulding, A. M., Larsen, S. E., and Petroff, A.: Size-resolved fluxes of sub-100-nm particles over forests, J. Geophys. Res.-Atmos., 114, D18212, 10.1029/2009jd012248, 2009.

Pryor, S. C., Spaulding, A. M., and Barthelmie, R. J.: New particle formation in the Midwestern USA: Event characteristics, meteorological context and vertical profiles, Atmos. Environ., 44, 4413-4425, 2010.

Pryor, S. C., Barthelmie, R. J., Sørensen, L. L., McGrath, J. G., Hopke, P., and Petäjä, T.: Spatial and vertical extent of nucleation events in the Midwestern USA: insights from the Nucleation In ForesTs (NIFTy) experiment, Atmos. Chem. Phys., 11, 1641-1657, doi:10.5194/acp-11-1641-2011, 2011.

Pryor, S. C., Barthelmie, R. J., and Schoof, J. T.: High-resolution projections of climate-related risks for the Midwestern USA, Clim. Res., 56, 61-79, 2013.

Roman, T. D., Novick, K., Brzostek, E., Dragoni, D., Rahman, F., and Phillips, R.: The role of isohydric and anisohydric species in determining ecosystem-scale response to severe drought, New Phytol., in review, 2014.

Saylor, R. D.: The Atmospheric Chemistry and Canopy Exchange Simulation System (ACCESS): model description and application to a temperate deciduous forest canopy, Atmos. Chem. Phys., 13, 69-715, doi:10.5194/acp-13-693-2013, 2013. 
Schmid, H. P., Grimmond, C. S. B., Cropley, F., Offerle, B., and Su, H.-B.: Measurements of $\mathrm{CO}_{2}$ and energy fluxes over a mixed hardwood forest in the midwestern United States, Agr. Forest Meteorol., 103, 357-374, 2000.

Stolzenburg, M. R., McMurry, P. H., Sakurai, H., Smith, J. N., Mauldin III, R. L., Eisele, F. L., and Clement, C. F.: Growth rates of freshly nucleated atmospheric particles in Atlanta, J. Geophys. Res., 110, D22S05, doi:10.1029/2005JD005935, 2005.
Westervelt, D. M., Pierce, J. R., Riipinen, I., Trivitayanurak, W., Hamed, A., Kulmala, M., Laaksonen, A., Decesari, S., and Adams, P. J.: Formation and growth of nucleated particles into cloud condensation nuclei: model-measurement comparison, Atmos. Chem. Phys., 13, 7645-7663, doi:10.5194/acp-13-76452013, 2013. 